\title{
ПРОФЕССИОНАЛЬНАЯ МОТИВАЦИЯ И УРОВЕНЬ ЭМОЦИОНАЛЬНОГО ВЫГОРАНИЯ У ПИЛОТОВ ГРАЖДАНСКОЙ АВИАЦИИ
}

\author{
Дарья С. Люкшина", Ксения А. Юрченко, Татьяна В. Капустина, \\ Мария А. Копенко, Юлия Г. Потребич \\ Федеральное государственное бюджетное образовательное учреж- \\ дение высшего образования «Тихоокеанский государственный меди- \\ цинский университет» Министерства здравоохранения Российской \\ Федерации, г. Владивосток, Российская Федерация \\ *E-mail: danyasergeevna@gmail.com
}

Проведено эмпирическое исследование профессиональной мотивачии и уровня эмоционального выгорания у летного состава международного аэропорта г. Владивостока. Группу исследования составили 40 пилотов гражданской авиации в возрасте 30-45 лет со стажем работы более 5 лет. Для оченки профессиональной мотивации использовались методика К. Замфира в модификации А. Реана «Изучение мотивачии профессиональной деятельности» и анкета для оценки мотивационного потенциала. Для определения уровня эмоционального выгорания проводилось тестирование с использованием опросника на выгорание $\mathrm{MBl}$, адаптированного H. Е. Водопьяновой, и методики «Диагностика уровня эмоционального выгорания» В. В. Бойко в модификации Е. П. Ильина.

Доказано, что пилоты гражданской авиачии заинтересованы в прочессе своей профессиональной деятельности, стараются быть частью рабочего коллектива и поддерживать дружеские отношения с коллегами, у них доминирует внутренняя профессиональная мотивация.

Исследование показало, что у преобладающего числа пилотов $(n=22)$ наблюдается средний уровень эмоционального выгорания. Они испытывают напряжение и усталость, возможен спад профессиональной эффективности, притупление когнитивных процессов, доминирует защитный механизм «избегание», возможен отказ от решения проблем. У трети респондентов отмечается высокий уровень эмочионального выгорания, характеризующийся возникновением физического и эмоционального утомления, не способного восстановиться после сна, исчерпыванием личностных ресурсов, возникновением чувства безысходности и беспомощности, появлением соматических нарушений, таких как: снижение аппетита, появление головных болей, нарушение цикла сна и бодрствования. У пятой части пилотов - низкий 
уровень эмоционального выгорания, у них не наблюдаются признаки данного синдрома, что характеризует их как достаточно адаптированных к своей профессиональной деятельности специалистов, самокритичных и откровенных, у них не наблюдается тенденции приукрашивать свой характер. Было установлено, что при увеличении показателей эмоционального выгорания направленность профессиональной мотивации от внутренней к внешней остается неизменной.

Ключевые слова: профессиональная мотивачия, внутренняя мотивация, внешняя мотивация, эмоциональное выгорание, деперсонализация, неудовлетворенность собой, редукция, эмоциональная отстраненность, пилоты, гражданская авиация.

Для цитирования: Люкшина Д. С., Юрченко К. А., Капустина Т. В., Копенко М. А., Потребич Ю. Г. Профессиональная мотивация и уровень эмоционального выгорания у пилотов гражданской авиации // Российский психологический журнал. - 2017. - Т. 14. - № 1. - С. 176-187.

\title{
PROFESSIONAL MOTIVATION AND THE LEVEL OF EMOTIONAL BURNOUT AMONG CIVIL AVIATION PILOTS
}

\author{
Dar'ya S. Lyukshina*, Kseniya A. Yurchenko, Tat'yana V. Kapustina, \\ Mariya A. Kopenko, Yuliya G. Potrebich \\ Pacific State Medical University, Vladivostok, Russian Federation \\ * Correspondence author. E-mail: danyasergeevna@gmail.com
}

The paper provides the results of the empirical study of professional motivation and the level of emotional burnout among flight crew members of Vladivostok international airport. The study involved 40 civil aviation pilots aged 30-45 years having more than 5 years of work experience. K. Zamfir's "Motivation of professional activity" technique (A. Rean's modification) and the questionnaire for assessing motivational potential were used for studying professional motivation. The level of emotional burnout was measured using the Maslach Burnout Inventory (MBI) in N. E. Vodop'yanova's modification and V. V. Boyko's "Diagnostics of the level of emotional burnout" technique (E. P. Ilyin's modification).

The study findings suggest that the civil aviation pilots (a) were interested in the process of their professional activities, (b) tried to be a part of the staff and to build 
friendly relationship with colleagues, and (c) had a prevailing intrinsic professional motivation.

The study showed that most pilots $(n=22)$ had an average level of emotional burnout. Moreover, the data revealed (a) stress and fatigue, (b) decrease in professional effectiveness, (c) cognitive decline, (d) avoidance as a defense mechanism, and (e) refusing problem solving. A third of the respondents had a high level of emotional burnout. These respondents noted physical and emotional fatigue, exhaustion of personal resources, feelings of hopelessness and helplessness, and somatic disorders (loss of appetite, headaches, and disturbances of sleep and wakefulness). A fifth of the pilots had a low level of emotional burnout. This finding suggests that these respondents are well-adjusted to their professional activities; they are selfcritical and frank. Besides, increasing the rates of emotional burnout did not change the orientation of motivation (from intrinsic to extrinsic).

Keywords: professional motivation, intrinsic motivation, extrinsic motivation, emotional burnout, depersonalization, self-dissatisfaction, reduction, emotional detachment, pilots, civil aviation.

For citation: Lyukshina D. S., Yurchenko K. A., Kapustina T. V., Kopenko M. A., Potrebich Yu. G. Professional motivation and the level of emotional burnout among civil aviation pilots. Rossiiskii psikhologicheskii zhurnal - Russian Psychological Journal, 2017, V. 14, no. 1, pp. 176-187 (in Russian).

Original manuscript received 22.07.2016

\section{Введение}

Профессиональная деятельность - деятельность человека в какой-либо профессии или производстве, нацеленная на результат. Каждый человек в профессии хочет развиваться и быть успешным в своем деле. Одной из главных причин, препятствующих развитию профессиональной деятельности, является эмоциональное выгорание [3, 17, 18, 19]. По мнению О. А. Злобиной, понятие эмоционального выгорания широко используется в научных исследованиях и негативно влияет на специалистов [6]. В работе А. О. Беловой изучение данного синдрома обусловлено появлением негативных установок, проявляющихся в различных сферах жизни [2]. Он характеризуется умственным и физическим истощением, постепенной утратой эмоциональной, когнитивной и физической энергии, снижением удовлетворенности результатами и личной отстраненностью. В работе Л. Р. Правдиной истощение ресурсов, снижение адаптационного потенциала приводят к неправильному принятию решений, выбору неверной стратегии действия, что приводит к негативным последствиям [11]. Детерминанты появления эмоционального выгорания 
у пилотов гражданской авиации имеют специфический характер: ненормированная организация труда, малочисленные карьерные должности, частая смена рабочего коллектива - экипажа, повышенная стрессогенная среда, высокие показатели плана и часов работы [16].

Важным и неотъемлемым компонентом успешной профессиональной деятельности является профессиональная мотивация. Мотивация - совокупность побуждающих факторов (мотивы, потребности, различные ситуативные факторы), определяющих активность личности и направленность деятельности [20]. Понятие профессиональной мотивации в современной отечественной и зарубежной психологии понимается разнообразно [7]. В структуре профессиональной мотивации большое значение отводится мотивации на рабочем месте - особому состоянию взаимодействия ситуационных и личностных факторов, благодаря которому происходит побуждение или прекращение определенной профессиональной деятельности [5]. В проблеме изучения профессиональной мотивации пилотов гражданской авиации на основе теоретических данных сделан вывод о сохранении мотивации с первых лет обучения в летных учреждениях для поддержания качества работы и выхода профессионально мотивированных специалистов [9]. Существует связь между синдромом эмоционального выгорания и профессиональными ролями специалистов. Если для данной роли требуется компромисс, или же стиль руководства вызывает исключительно негативное отношение, при отсутствии поддержки происходят личностный конфликт и перегрузка, что способствует развитию синдрома [10]. Изучение взаимосвязи данных понятий способствует прогнозированию и поддержанию эффективной трудовой деятельности и сохранению психологического здоровья.

\section{Методы}

Исследование проводилось с 40 пилотами гражданской авиации, в возрасте 30-45 лет, со стажем работы более 5 лет. В исследовании использовались методы тестирования и анкетирования, представленные следующими методиками: «Изучение мотивации профессиональной деятельности» (К. Замфир, в модификации А. Реана); анкета для оценки мотивационного потенциала; опросник на выгорание МBI, адаптирован Н. Е. Водопьяновой; «Диагностика уровня эмоционального выгорания» (В. В. Бойко, в модификации Е. П. Ильина).

\section{Результаты исследования}

Сопоставив результаты по методикам - К. Замфира в модификации А. Реана «Изучение мотивации профессиональной деятельности» и «Анкеты оценки мотивационного потенциала», были получены следующие данные. У 18 пилотов преобладает внутренняя мотивация (ВМ). Они вовлечены в профессиональную 
деятельность, нацелены не только на результат, но и на качество и процесс выполняемой работы, склонны ставить себе повышенные задачи и выполнять их, получая от этого удовольствие [4]. У 8 пилотов преобладает внешняя положительная мотивация (ВПМ), они нацелены на карьерный рост, на положительное подкрепление за свою деятельность, не всегда получают удовлетворение от самого процесса труда. У 10 пилотов ВМ и ВПМ равны, они получают удовольствие от самого процесса труда, нацелены на карьерный рост и социальное одобрение. У 4 пилотов преобладает внутренняя отрицательная мотивация (ВОМ), они выполняют свою деятельность без интереса, присутствует страх наказания или социального неодобрения. Таким образом, у данных пилотов гражданской авиации доминирует внутренняя мотивация, они заинтересованы в процессе деятельности, нацелены на получение результата, являются частью коллектива, поддерживают хорошие отношения с коллегами.

По методике «Опросник на выгорание МBI, адаптированный Н. Е. Водопьяновой» у 22 пилотов наблюдается слабовыраженное эмоциональное истощение. Они эффективно работают, испытывают положительные эмоции в работе и к коллегам, не имеют выраженных соматических признаков. У 18 пилотов средне выражен синдром эмоционального выгорания, респонденты испытывают некоторые психологические и соматические изменения в состоянии, наблюдается небольшой спад в деятельности. У 34 пилотов наблюдается слабовыраженная деперсонализация, у них отсутствуют изменения в восприятии окружающего мира, они ориентируются во времени, не испытывают равнодушие к окружающим людям и коллегам, испытывают разные эмоции от негативных до положительных. У 6 пилотов средне выражена деперсонализация, у них может возникать чувство неузнаваемости окружающей обстановки или привычного вида деятельности, притупление чувства юмора, снижение чувствительности, возможны проявления физиологических изменений [8]. У 28 пилотов наблюдается сильно выраженная редукция личных достижений - негативно оценивают свои профессиональные результаты и компетентность, наблюдается тенденция к снятию ответственности за работу, возможно понижение мотивации, отстранение от коллег и работы. У 12 пилотов - средне выраженная редукция личных достижений, уменьшение удовлетворения результатами, появление чувства недовольства собой, пренебрежение служебными обязанностями.

По методике «Диагностика уровня эмоционального выгорания» (В. В. Бойко, в модификации Е. П. Ильина) у 24 пилотов преобладает несложившийся симптом неудовлетворенности собой, работники удовлетворены профессией, принимают участие в решении коллективных задач, у них отсутствует механизм переноса негативных эмоций. У 16 пилотов отмечается складывающийся 
симптом неудовлетворенности собой, специалисты периодически испытывают неудовлетворенность собой и своими профессиональными результатами, могут отказываться от участия внутри коллективных дел и испытывать негативные эмоции при возложении на них обязанностей [13]. Преобладает число пилотов ( $\mathrm{n}=30$ ) с несложившимся симптомом загнанности в клетку, они легко решают проблемы, обдумывают неудовлетворительные аспекты работы и составляют план для получения эффективной стратегии. У 10 пилотов выявлен складывающийся симптом загнанности в клетку, они находятся в профессиональном тупике, но обладают личностными ресурсами для преодоления возникших трудностей. У 20 пилотов - несложившийся симптом редукции профессиональных обязанностей, они выполняют свои обязанности и поставленные задачи в полном объеме, даже если они требуют эмоциональных затрат. У 20 пилотов выявлен складывающийся симптом редукции профессиональных обязанностей, они пытаются облегчать поставленные задачи, избегать ответственности, могут не выполнять поставленный план, если он энерго- и эмоционально затратный. У 26 пилотов наблюдается несложившийся симптом эмоциональной отстраненности, в процессе трудовой деятельности они испытывают и показывают положительные и отрицательные эмоции, чувства [14]. У 14 пилотов выявлен складывающийся симптом эмоциональной отстраненности, они могут не испытывать сочувствия и сопереживания к коллегам, быть раздражительными, резкими, грубыми. У 28 пилотов - несложившийся симптом личностной отстраненности, они удовлетворены работой, микросоциумом, убеждены, что являются социальной ценностью, проявляют заинтересованность и расширяют интересы. У 12 пилотов выявлен складывающийся симптом личностной отстраненности, отсутствует инициатива, интересы, контакты с социумом, может возникать желание ухода из профессии.

Таким образом, у преобладающего числа пилотов ( $\mathrm{n}=22)$ наблюдается средний уровень эмоционального выгорания, они испытывают напряжение, физическую и эмоциональную усталость, избегают мыслей о возможных неудачах, могут отказываться от решения проблем; возможен спад профессиональной эффективности и притупление интеллектуальных и когнитивных процессов [1]. У 14 респондентов отмечается высокий уровень эмоционального выгорания, характеризующийся возникновением физического и эмоционального утомления, не способного восстановиться после сна, отсутствием личностных ресурсов, возникновением чувства безысходности и беспомощности, появлением соматических нарушений - снижением аппетита, появлением головных болей, нарушением сна. Специалисты не уверены в себе, чувствительны к любым внешним факторам, имеют тенденцию к тщательной проверке каждого вида деятельности, могут иметь зависимую позицию, ориентированную на мнение 
социума [12]. У 8 пилотов выявлен низкий уровень эмоционального выгорания, они адаптированы к деятельности, самокритичны, откровенны, с отсутствием тенденции приукрашивать свой характер.

С помощью коэффициента ранговой корреляции Ч. Спирмена выявлена взаимосвязь между типами профессиональной мотивации и уровнями эмоционального выгорания у пилотов гражданской авиации по методикам (таблицы 1, 2) [15].

При увеличении показателей внутренней мотивации (медиана $=4,8$ ) наблюдается увеличение значений по шкале «Редукция личных достижений» (медиана = 35). Данная корреляционная связь может быть связана с тем, что чем выше заинтересованность в эффективности результата своей деятельности, и не достижение его, тем выше обесценивание своего труда и недооценка себя.

Таблица 1.

Корреляционные связи профессиональной мотивации с уровнями эмоционального выгорания по методике Н. Е. Водопьяновой

Table 1.

Professional motivation by the levels of emotional burnout:

N. E. Vodop'yanova's technique

\begin{tabular}{|c|c|c|c|}
\hline $\begin{array}{c}\text { Сравниваемые показатели } \\
\text { Indices }\end{array}$ & $\begin{array}{l}\text { Количество } \\
\text { респондентов } \\
\text { Respondents } \\
\text { (n) }\end{array}$ & $\begin{array}{l}\text { Коэффичиент } \\
\text { ранговой } \\
\text { корреляции } \\
\text { Rank correlation } \\
\text { coefficient }\end{array}$ & $\begin{array}{c}\text { Достоверность } \\
\text { (односторон- } \\
\text { ний критерий) } \\
\text { Reliability } \\
\text { (one-tailed test) }\end{array}$ \\
\hline $\begin{array}{c}\text { BM \& Редукция личных } \\
\text { достижений } \\
\text { Intrinsic motivation \& } \\
\text { Reduction of personal } \\
\text { achievements }\end{array}$ & 40 & 0,41 & 0,004 \\
\hline $\begin{array}{c}\text { ВПМ \& Деперсонализация } \\
\text { Extrinsic positive motivation \& } \\
\text { Depersonalization }\end{array}$ & 40 & 0,34 & 0,02 \\
\hline $\begin{array}{c}\text { ВОМ \& Эмоциональное } \\
\text { истощение } \\
\text { Intrinsic negative } \\
\text { motivation \& } \\
\text { Emotional exhaustion }\end{array}$ & 40 & 0,31 & 0,03 \\
\hline $\begin{array}{c}\text { ВОМ \& Деперсонализация } \\
\text { Intrinsic negative motivation \& } \\
\text { Depersonalization }\end{array}$ & 40 & 0,37 & 0,01 \\
\hline
\end{tabular}


Таблица 2.

Корреляционные связи профессиональной мотивации с уровнями эмоционального выгорания по методике В. В. Бойко

Table 2.

Professional motivation by the levels of emotional burnout: V. V. Boyko's technique

\begin{tabular}{|c|c|c|c|}
\hline $\begin{array}{c}\text { Сравниваемые показатели } \\
\text { Indices }\end{array}$ & $\begin{array}{c}\text { Количество } \\
\text { респондентов } \\
\text { Respondents } \\
\text { (n) }\end{array}$ & \begin{tabular}{|c|} 
Коэффициент \\
ранговой \\
корреляции \\
Rank correlation \\
coefficient \\
\end{tabular} & $\begin{array}{c}\text { Достоверность } \\
\text { (односторонний } \\
\text { критерий) } \\
\text { Reliability } \\
\text { (one-tailed test) } \\
\end{array}$ \\
\hline $\begin{array}{l}\text { ВОМ \& Неудовлетворенность } \\
\text { собой } \\
\text { Intrinsic negative motivation \& } \\
\text { Self-dissatisfaction }\end{array}$ & 40 & 0,48 & 0,001 \\
\hline $\begin{array}{c}\text { ВОМ \& Загнанность в клетку } \\
\text { Intrinsic negative motivation \& } \\
\text { Driving into the cage }\end{array}$ & 40 & 0,46 & 0,001 \\
\hline $\begin{array}{c}\text { ВОМ \& Редукция профессио- } \\
\text { нальных обязанностей } \\
\text { Intrinsic negative motivation \& } \\
\text { Reduction of professional } \\
\text { duties }\end{array}$ & 40 & 0,29 & 0,04 \\
\hline $\begin{array}{c}\text { ВОМ \& Эмоциональная } \\
\text { отстраненность } \\
\text { Intrinsic negative motivation \& } \\
\text { Emotional detachment }\end{array}$ & 40 & 0,26 & 0,05 \\
\hline $\begin{array}{c}\text { ВОМ \& Личностная } \\
\text { отстраненность } \\
\text { Intrinsic negative motivation \& } \\
\text { Personal detachment }\end{array}$ & 40 & 0,26 & 0,05 \\
\hline
\end{tabular}

При увеличении значений ВПМ (медиана $=4,2$ ) увеличиваются показатели по шкале «Деперсонализация» (медиана = 13), что может говорить о том, что чем выше значимость материального или иного вида поощрения, и его не получение, тем сильнее изменяются взаимоотношения с коллегами и окружающими, и положительные эмоции меняются на негативные.

При увеличении показателей ВОМ (медиана = 3,8) возрастают показатели по шкалам «Эмоциональное истощение» (медиана = 22), «Деперсонализация», «Неудовлетворенность собой» (медиана =8), «Загнанность в клетку» (медиана = 3), 
«Редукция профессиональных обязанностей» (медиана = 14), «Эмоциональная отстраненность» (медиана = 10), «Личностная отстраненность» (медиана = 5). Полученные статистические результаты указывают на то, что чем выше заинтересованность не только результатом, но и процессом деятельности и вовлеченности в свою работу, тем ниже проявление негативных эмоций к своим обязанностям, появление чувства безнадежности и изменение личностных ценностей и интересов.

Поскольку по показателям ВМ и ВПМ не было получено корреляционных связей с результатами по методике В. В. Бойко, можно предположить, что пилоты гражданской авиации вовлечены в профессиональную деятельность, увлечены процессом труда, участвуют в жизни коллектива, менее подвержены появлению синдрома эмоционального выгорания. Таким образом, результат взаимосвязи профессиональной мотивации и эмоционального выгорания, возможно, обусловлен личностными особенностями пилотов гражданской авиации.

\section{Выводы}

Пилоты в профессиональной деятельности заинтересованы процессом труда, нацелены на получение результата, стараются быть частью рабочего коллектива и поддерживать коммуникации с коллегами. У них преобладают внутренняя мотивация и низкий уровень эмоционального выгорания. При увеличении показателя эмоционального выгорания направленность профессиональной мотивации от внутренней к внешней остается неизменной.

\section{Литература}

1. Бабанов С. А. Синдром «эмоционального выгорания» // Вестник КГУ имени Н. А. Некрасова. - 2010. - № 2. - С. 294-301.

2. Белова А. О., Кадыров Р. В., Корнилова Д. С., Скоробач Т. В. Профессиональная мотивация и уровень эмоционального выгорания у преподавателей вуза (на примере преподавателей медицинского вуза) // Международный журнал прикладных и фундаментальных исследований. - 2014. № 12-1. - С. 66-71.

3. Богданова Е. В. Профилактика эмоционального выгорания как условие профессионального развития и саморазвития сотрудников ГАУЗ «РЦПБ СПИД И ИЗ МЗ РТ» // Социальное благополучие человека в современном мире: сборник материалов Международной научной школы. - Казань: Изд-во КНИТУ, 2014. - С. 29-33.

4. Бодров В. А. Психология профессиональной пригодности: учебное пособие для вузов. - М.: ПЕР СЭ, 2006. - 511 с. 
5. Захарова Т. И., Гаврилова С. В. Мотивация трудовой деятельности:учебно-методический комплекс. - М.: Изд. центр ЕАОИ, 2008. - 216 с.

6. Злобина О. А. Влияние различной степени эмоционального выгорания индивидуума на стоматологический статус // Тихоокеанский медицинский журнал. - 2014. - № 3. - С. 31-33.

7. Кибанова А. Я. Управление персоналом: теория и практика. Мотивация и стимулирование трудовой деятельности: учебно-практическое пособие. - М.: Проспект, 2015. - 64 с.

8. Коваленко П. А., Пономаренко В. А., Чунтул А. В. Учение об иллюзиях полета: Основы авиационной делиалогии. - М.: Изд-во Института психологии РАН, 2007. - 461 с.

9. Пономаренко В. А. Личность летчика - фундамент профессиональной надежности. - М., 2007.

10. Пономаренко В. А. Страна Авиация: черное и белое. - М.: Наука, 1995.

11. Правдина Л.Д., Шипитько О. Ю., Алиев Ш. Г. Экзистенциальная исполненность и направленность деятельности у специалистов гражданской авиации // Российский психологический журнал. - 2016. - № 1. - С. 61-75.

12. Современные проблемы исследования синдрома выгорания у специалистов коммуникативных профессий: коллективная монография / Под ред. В. В. Лукьянова, Н. Е. Водопьяновой, В. Е. Орла, С. А. Подсадного, Л. Н. Юрьевой, С. А. Игумнова; Курск. гос. ун-т. - Курск, 2008. - 336 с.

13. Фетискин Н. П., Козлов В. В., Мануйлов Г. М. Социально-психологическая диагностика развития личности и малых групп. - М.: Изд-во Института Психотерапии, 2002. - 490 с.

14. Целуйко В. М. Психологические основы педагогического общения: пособие для студентов и педагогов. - М.: Гуманитар. изд. центр ВЛАДОС, 2007. - 295 с.

15. Шишлянникова Л. М. Применение корреляционного анализа в психологии // Психологическая наука и образование. - 2009. - № 1. - С. 98-107.

16. Яхно А. А. Профессиональный стресс и эмоциональное выгорание в системе здравоохранения Российской Федерации // Альм. сестринского дела. - 2009. - № 2. - С. 34-39.

17. Maslach C. Job Burnout // Annual Review of Psychology. - 2001. - V. 52. pp. 397-422.

18. Maslach C. M. Job burnout: new directions in research and intervention // Current Directions in Psychological Science. - 2003. - V. 12. - pp. 189-192.

19. Van Yperen N. W. Informational support, equity and burnout:The moderatin effect of self-efficacy // J. of Occupat. Psychol. - 2004. - V.71. - no. 1. - pp. 29-33.

20. Wofford J. C. Cognitive-affective stress response: effects of individual stress propensity on physiological and psychological indicator of strain // Psychological Reports. - 2001. - V. 88. - no. 3. - pp. 71-75. 


\section{References}

1. Babanov S. A. Emotional burnout syndrome. Vestnik KGU imeni N. A. Nekrasova - Nekrasov Kostroma State University Bulletin, 2010, no. 2, pp. 294-301 (in Russian).

2. Belova A. O., Kadyrov R. V., Kornilova D. S., Skorobach T. V. Professional motivation and the level of emotional burnout among university teachers (on the example of medical university teachers). Mezhdunarodnyi zhurnal prikladnykh i fundamental'nykh issledovanii - International Journal of Applied and Fundamental Research, 2014, no. 12-1, pp. 66-71 (in Russian).

3. Bogdanova E. V. Preventing emotional burnout as a condition of professional development and self-development of employees of the Center for Prevention and Control of AIDS and Infectious Diseases, Ministry of Public Health, Republic of Tatarstan. In: Sotsial'noe blagopoluchie cheloveka v sovremennom mire: sbornik materialov Mezhdunarodnoi nauchnoi shkoly [Social well-being in the modern world]. Kazan, Kazan National Research Technological University Publ., 2014, pp. 29-33.

4. Bodrov V. A. Psikhologiya professional'noi prigodnosti [The psychology of vocational aptitude]. Moscow, PER SE Publ., 2006. 511 p.

5. Zakharova T. I., Gavrilova S. V. Motivatsiya trudovoi deyatel'nosti: uchebnometodicheskii kompleks [Labour activity motivation]. Moscow, EAOI Publ., 2008. $216 \mathrm{p}$.

6. Zlobina O. A. The influence of the level of the individual's emotional burnout on a dental status. Tikhookeanskii meditsinskii zhurnal-Pacific Medical Journal, 2014, no. 3, pp. 31-33 (in Russian).

7. Kibanova A. Ya. Upravlenie personalom: teoriya i praktika. Motivatsiya i stimulirovanie trudovoi deyatel'nosti [Personnel management: theory and practice. Motivating and stimulating labour activity]. Moscow, Prospekt Publ., 2015. 64 p.

8. Kovalenko P. A., Ponomarenko V. A., Chuntul A. V. Uchenie ob illyuziyakh poleta: Osnovy aviatsionnoi delialogii [The theory of flight illusions: fundamentals of aviation delialogy]. Moscow, Institute of Psychology RAS Publ., 2007.461 p.

9. Ponomarenko V. A. Lichnost' letchika - fundament professional'noi nadezhnosti [A pilot's personality as a basis for professional reliability]. Moscow, 2007.

10. Ponomarenko V. A. Strana Aviatsiya: chernoe i beloe [An aviation country: black and white]. Moscow, Nauka Publ., 1995.

11. Pravdina L. D., Shipit'ko O. Yu., Aliev Sh. G. Existential fulfillment and activity orientation in civil aviation personnel. Rossiiskii psikhologicheskii zhurnal Russian Psychological Journal, 2016, no. 1, pp. 61-75 (in Russian).

12. Luk'yanov V. V., Vodop'yanova N. E., Oryol V. E., Podsadniy S. A., Yur'eva L. N., Igumnov S. A. (eds.) Sovremennye problemy issledovaniya sindroma 
vygoraniya u spetsialistov kommunikativnykh professii [Modern problems of studying burnout syndrome in specialists in communicative professions]. Kursk, 2008. 336 p.

13. Fetiskin N. P., Kozlov V. V., Manuilov G. M. Sotsial'no-psikhologicheskaya diagnostika razvitiya lichnosti imalykh grupp [Socio-psychological diagnostics of the development of the person and small groups]. Moscow, Institute of Psychotherapy Publ., 2002. $490 \mathrm{p}$.

14. Tseluiko V. M. Psikhologicheskie osnovy pedagogicheskogo obshcheniya [Psychological fundamentals of pedagogical communication]. Moscow, VLADOS Publ., 2007. 295 p.

15. Shishlyannikova L. M. Applying correlation analysis in psychology. Psikhologicheskaya nauka i obrazovanie - Psychological Science and Education, 2009, no. 1, pp. 98-107 (in Russian).

16. Yakhno A. A. Professional stress and emotional burnout in the health care system of the Russian Federation. Al'm. sestrinskogo dela - Almanac of Nursing, 2009, no. 2, pp. 34-39 (in Russian).

17. Maslach C. Job Burnout. Annual Review of Psychology, 2001, V. 52, pp. 397-422.

18. Maslach C. M. Job burnout: new directions in research and intervention. Current Directions in Psychological Science, 2003, V. 12, pp. 189-192.

19. Van Yperen N. W. Informational support, equity and burnout: The moderatin effect of self-efficacy. J. of Occupat. Psychol., 2004, V. 71, no. 1, pp. 29-33.

20. Wofford J. C. Cognitive-affective stress response: effects of individual stress propensity on physiological and psychological indicator of strain. Psychological Reports, 2001, V. 88, no. 3, pp. 71-75. 